\title{
Исследование факторов влияния на особенности управления персоналом гостиничных предприятий: концептуальные аспекты
}

\author{
Шостак М.А., Яковлева М.А. \\ Крымский федеральный университет им. В.И. Вернадского \\ Россия, 295007, Республика Крым, г. Симферополь, пр-т Академика Вернадского, 4 \\ E-mail: shostakma@inbox.ru,mariya67.70@mail.ru
}

\begin{abstract}
Аннотация. В работе представлена концептуальная модель влияния отраслевых факторов индустрии гостеприимства на особенности управления персоналом гостиничных предприятий в современных условиях. Рассмотрены отличительные характеристики деятельности предприятий индустрии гостеприимства. Выявлены и проанализированы факторы управления персоналом, а также обоснована причинно-следственная связь влияния отраслевых факторов на особенности управления персоналом. Методом дифференциации сгруппированы особенности управления персоналом в зависимости от признаков отрасли и выделенных критериев системы управления персоналом гостиничной индустрии в современных условиях.
\end{abstract}

Ключевые слова: управление персоналом, гостиничное предприятие, индустрия гостеприимства и туризма, особенности, факторы, пандемия Covid-19, коронакризис, цифровая трансформация, цифровизация.

Для цитирования: Шостак М.А., Яковлева М.А. 2021. Исследование факторов влияния на особенности управления персоналом гостиничных предприятий: концептуальные аспекты. Экономика. Информатика, 48 (2): 287-298. DOI 10.52575/2687-0932-2021-48-2-287-298.

\section{Research of factors influencing features of human resource management of hotels: conceptual aspects}

\author{
Marina A. Shostak, Maria A. Yakovleva \\ V.I. Vernadsky Crimean Federal University \\ 4 Acad. Vernadsky ave, Simferopol, Crimean Republic, 295007, Russia \\ E-mail: shostakma@inbox.ru, mariya67.70@mail.ru
}

\begin{abstract}
The paper presents a conceptual framework showing the influence of the hospitality industry's specific factors on the personnel management's peculiar features in lodging establishments under the presentday conditions, i.e. in the context of the digital transformation of the hotel business and the crisis phenomena of the Covid-19 pandemic. Considered are the specific features of the activities performed by the hospitality industry's establishments. The authors have studied the functional patterns of business processes in the hotel industry determining the specifics of labor activity. Besides, they have identified and analyzed the factors of personnel management, and also substantiated the causal relationship of the identified industry factors' influence on the features of personnel management. The differentiation method has been used to group the features of personnel management according to the industry's characteristic features and the selected criteria of the hotel industry's personnel management system under the present-day conditions. The considered research topic will be of interest to specialists working in the sphere of personnel management and influencing the process of human resource management at hospitality industry establishments.
\end{abstract}

Keywords: human resource management, hotel enterprise, hospitality and tourism industry, features, factors, Covid-19 pandemic, coronavirus, digital transformation, digitalization. 
For citation: Shostak M.A., Yakovleva M.A. 2021. Research of factors influencing features of human resource management of hotels: conceptual aspects. Economics. Information technologies, 48 (2): 287-298 (in Russian). DOI 10.52575/2687-0932-2021-48-2-287-298.

\section{Введение}

В современных условиях, характеризующихся стремительным развитием цифровых технологий, неопределенностью экономической и политической обстановки, а также общей нестабильностью эпидемиологической ситуации, набирает популярность концепция VUCA (Volatility - нестабильность, Uncertainty - неопределенность, Complexity - сложность, Ambiguity неоднозначность). Данный подход, основанный на поиске эффективных решений в условиях нестабильности и быстрых изменений в мире, подчеркивает особое значение необходимости учета всего многообразия факторов, способных снизить уровень уязвимости предприятий. Скорость и качество происходящих изменений заставляют современные предприятия пересматривать и менять подходы к управлению персоналом: необходимо постоянно наращивать навыки и компетенции, повышающие скорость, гибкость и вовлеченность сотрудников, совершенствовать систему управления персоналом, используя цифровые инструменты и технологии, способные повысить ее адаптивность и эффективность. Происходящие процессы неоднородны в различных отраслях и сферах деятельности. Особенно чувствительна к сложившимся условиям сфера гостеприимства и туризма.

При исследовании вопросов управления персоналом гостиничных предприятий в современных условиях, в фокус внимания специалистов попадают следующие аспекты:

- принципы, функции, система и характерные черты управления персоналом гостиничных предприятий [Архипова, 2019; Лустина, Арутюнян, 2018; Мысова, 2015; Павлова, Никольская, 2016; Савчишкина, 2019; Стахно, 2019; Чуваткин, Горбатов, 2020 и др.],

- продолжающаяся цифровая трансформация бизнеса, требующая пересмотра подходов к управлению персоналом [Вертинова, Бородина, Воронкова, 2019; Кузнецова, 2019; Мартынова, Камшилов, 2019; Нагибина, Щукина, 2017; Семина, 2020; Шостак, 2020; Яковлева, 2020 и др.],

- особо актуальные проблемы, связанные с влиянием пандемии Covid-19 как на рынок труда в целом, так и на систему управления персоналом в частности [Гордеева, Бурова, 2020; Михайлов, Федулов, 2020; Сайфуллина, Комнатная, 2020 и др.].

Вместе с тем анализ научных трудов, посвящённых вопросам управления персоналом гостиничных предприятий в современных условиях, позволяет сделать вывод о том, что исследуемая проблема имеет недостаточную степень научной разработанности, требует дополнительного изучения и систематизации знаний в отношении дифференциации особенностей управления персоналом индустрии гостеприимства и отраслевых факторов влияния с целью дальнейшей группировки и представления концептуальной схемы их взаимосвязи.

Таким образом, цель настоящего исследования состоит в разработке концептуальной модели, отражающей причинно-следственные связи, возникающие в процессе влияния факторов индустрии гостеприимства на особенности управления персоналом предприятий отрасли в современных условиях.

\section{Объекты и методы исследования}

В ходе исследования использованы общенаучные и специальные методы, применяющиеся на теоретическом и эмпирическом уровнях познания: системный подход, методы индукции и дедукции, анализа и синтеза, наблюдения и аргументации (при исследовании современной общеэкономической ситуации в индустрии гостеприимства в 
контексте организационных аспектов управления предприятиями отрасли); абстрагирования (при определении отраслевых факторов, оказывающих наиболее существенное воздействие на политику управления персоналом гостиничных предприятий); экспертной оценки (при анализе практических аспектов управления персоналом гостиничных предприятий региона); сравнения и классификации (при сопоставлении и проведении сравнительного анализа подходов к управлению персоналом в зависимости от формы организации управления гостиничным предприятием на основе выделенных критериев); группировки (при выявлении зависимостей факторов и особенностей управления персоналом гостиничных предприятия); статистические методы (при исследовании контуров переменных величин динамики hh.индексов на рынке труда); метод концептуального моделирования (при построении концептуальной модели влияния отраслевых факторов индустрии гостеприимства на особенности управления персоналом в современных условиях).

\section{Результаты и их обсуждение}

Управление персоналом гостиничных предприятий определяется спецификой предоставляемого гостиничного продукта, который состоит из услуг (основных и дополнительных), оказываемых сотрудниками, следствием чего является высокая степень зависимости качества обслуживания и эффективности деятельности предприятия от человеческого фактора. Однако во многом определяющая роль человеческого фактора не является исключительной: на деятельность гостиничного предприятия в области управления персоналом способны оказывать влияние как внутренние факторы, связанные с организацией и ведением бизнеса (специализация, категория, форма собственности, организации управления, размер предприятия), так и внешние, определяющие условия его функционирования и характеризующие особенности и состояние индустрии гостеприимства (сезонность, состояние рынка, в том числе рынка труда, общеэкономическая, эпидемиологическая ситуация, современные тенденции в развитии смежных отраслей и др.).

Ввиду вышесказанного, возникает необходимость выделить и проанализировать ключевые отраслевые факторы, предопределяющие особенности управления персоналом гостиничного предприятия в современных условиях.

Специфичность услуг является основным фактором, оказывающим влияние на процесс управления персоналом гостиничного предприятия, вследствие таких особенностей как: нематериальный характер услуги (неосязаемость), неразрывность процесса производства и потребления (неотделимость от источника), непостоянство качества, отсутствие владения, несохраняемость. Из перечисленных особенностей услуг наибольшее влияние на процессы, связанные с управлением персоналом, оказывают: неразрывность производства и потребления, непостоянство качества, непосредственно связанные с человеческим фактором. В связи с этим можно выделить особенность управления персоналом гостиничного предприятия, которая заключается в необходимости обеспечения клиентоориентированности персонала.

Клиентоориентированность персонала - комплексная профессиональная компетенция, состоящая из совокупности взаимосвязанных элементов (знаний, умений, навыков, мотивации, ценностей, установок, личностных качеств, поведения), характеризующей качество рабочей силы, выполняющей функции базового компонента и фактора в формировании профессиональных компетенций работников, а также в стратегии установления и поддержания взаимоотношений с клиентами [Шавровская, 2011].

Реализация стратегии клиентоориентированности предполагает проявление внимания не только в отношении внешних, но и внутренних клиентов - персонала организации, который в конечном итоге должен обеспечить наилучшее удовлетворение потребностей клиентов. Основными инструментами при данном подходе выступают корпоративная культура и внутренний (внутриорганизационный) маркетинг, представляющий собой «вид управленческой 
деятельности, направленный на оптимизацию внутренней среды предприятия путем использования маркетингового подхода к управлению персоналом (средствами маркетинга)» [Тимиргалеева, Гришин, Шостак, 2015]. Результатом внутреннего маркетинга является вовлеченный персонал, обладающий высоким уровнем клиентоориентированности, обеспечивающий высокие показатели качества обслуживания, лояльности клиентов, укрепление бренда предприятия (в том числе HR-бренда) и, как следствие, повышение прибыли.

B складывающихся условиях в отношении персонала гостиничных предприятий все большее значение приобретают, не только специализированные профессиональные компетенции, соответствующие занимаемой должности (hard skills), но и soft skills, характеризующие неспециализированные умения и навыки взаимодействия и эффективного общения персонала с клиентами. Среди soft skills, наиболее значимых для персонала индустрии гостеприимства, можно выделить: личная и командная ответственность; эмоциональный интеллект и эмпатия; активное слушание; вербальная и невербальная коммуникация; управление стрессом (стрессоустойчивость).

Таким образом, можно выделить два направления HR-работы, определяющие особенности управления персоналом на предприятиях индустрии гостеприимства: особые требования к персоналу в части soft skills; поддержание и развитие внутренней клиентоориентированности персонала посредством применения дополнительных HR-инструментов и технологий.

Сезонность. Гостиничная индустрия имеет высокую степень зависимости от данного фактора, так как сезонность является отраслевым фактором и проявляется в количестве клиентов, их расходах, в загрузке номерного фонда. В высокий сезон возникает количественная потребность привлечения сезонных работников. На рис. 1 представлена динамика и взаимосвязь индекса сезонности и показателя, характеризующего спрос на сотрудников отрасли (hh.индекс [Статистика HeadHunter по Республике Крым, 2021]), на примере Республики Крым за 2019 год.

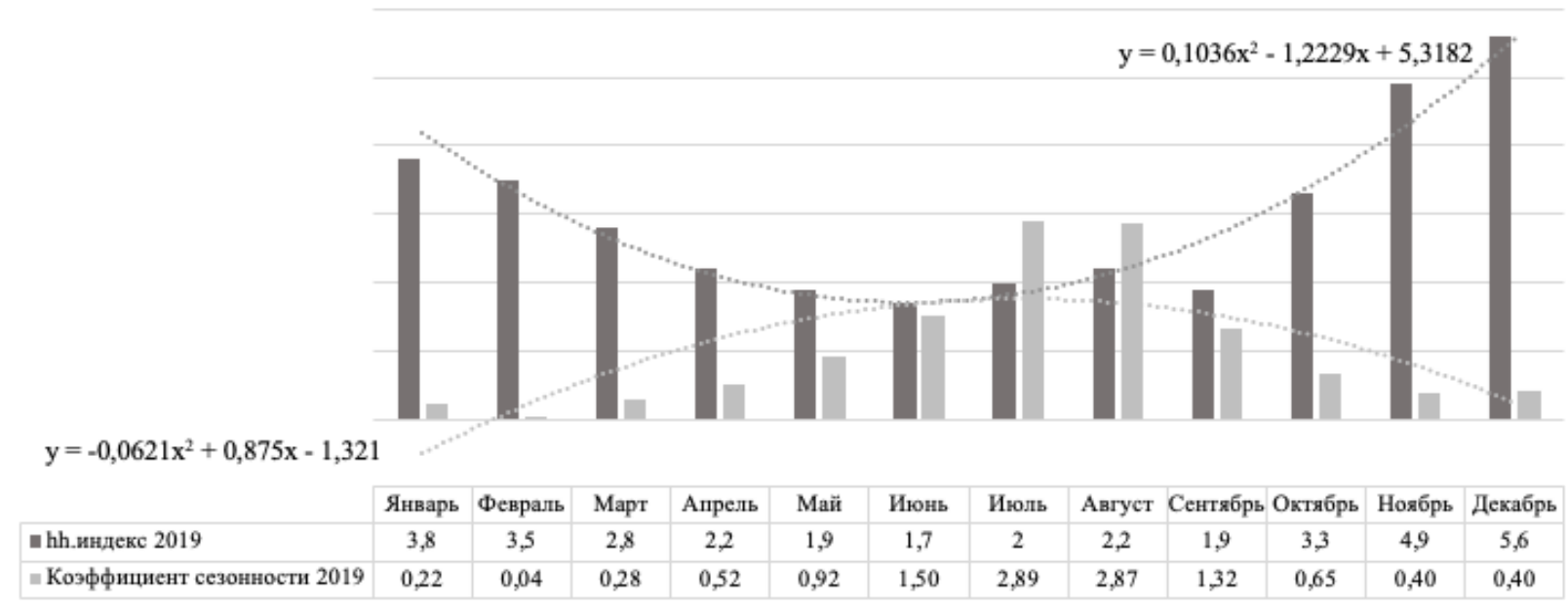

Рис. 1. Динамика hh.индекса индустрии гостеприимства (профессиональной сферы «туризм, гостиницы, рестораны») и коэффициента сезонности в Республике Крым (2019 г.)

Fig. 1. Dynamics of the hh.index of the hospitality industry (the professional sphere including tourism, hotels and restaurants) and the seasonal coefficient in the Republic of Crimea (2019)

Для рассматриваемого туристского региона данная ситуация была типичной на протяжении последних лет (2015-2019 гг.); кардинальные изменения произошли в 2020 году и были связаны с глобальным коронакризисом. Динамика hh.индекса показывает, как изменилось общее количество вакансий, насколько изменился спрос на сотрудника у работодателей в целом по рынку (профессиональная сфера: туризм, гостиницы, рестораны). 
Рассчитывается за текущий месяц относительно такого же месяца прошлого года. Из представленного графика видно, что между hһ.индексом и сезонностью существует обратная зависимость, свидетельствующая о такой характерной черте индустрии гостеприимства, как сезонность открытия вакансий.

Основная особенность управления персоналом, сформированная под влиянием данного фактора, заключается в дифференцированном подходе к выстраиванию HR-процессов в отношении сезонных и постоянных сотрудников. Данный подход заключается в следующих действиях в управлении персоналом, направленных на оптимизацию работы сезонных и постоянных сотрудников:

- ускоренная программа адаптации и обучения сезонных сотрудников;

- проведение welcome-тренингов с сезонными работниками перед началом сезона;

- применение дополнительных инструментов мотивации в низкий сезон с целью удержания постоянных работников и поддержания высокого уровня вовлеченности (гибкий и индивидуальный график работы, поддержание корпоративного духа, участие в управлении);

- активизация применения обучающих программ, направленных на повышение квалификации постоянного персонала, в период низкого сезона;

- ограничение (низкий уровень) инвестиций в сезонный персонал.

На решение проблемы сезонности в отношении персонала способны повлиять мотивационные программы и оптимизация штатного расписания. А совокупное применение предложенных действий и эффективная HR-политика в области привлечения, найма и обучения сезонного персонала, позволит минимизировать последствия фактора сезонности и сбалансировать работу сезонных и постоянных сотрудников.

Характер рынка труда индустрии гостеприимства и туризма. Ситуация на современном рынке труда характеризуется рядом основных тенденций: повышение значимости имиджа предприятий-работодателей в процессе поиска работы соискателями; растущий приоритет гибкого графика работы; рост популярности технологий аутсорсинга и аутстафинга при закрытии вакансий; развитие многостороннего сотрудничества с учебными заведениями с целью подбора и развития персонала и др. Данные тенденции подталкивают современные гостиничные предприятия к активному использованию инструментов HRбрендинга, представляющего собой комплекс целенаправленных мероприятий по формированию положительного имиджа работодателя с целью постоянного привлечения лучших специалистов отрасли, что особенно актуально в низкий сезон.

В силу тесной взаимосвязи характера рынка труда индустрии туризма и гостеприимства с таким фактором как сезонность, региональные особенности рынка труда могут иметь различные характерные черты, присущие тому или иному туристскому региону: прямая связь между состоянием рынка труда с туристским сектором экономики региона; сезонные колебания занятости в зависимости от туристского региона (см. рис. 1); неравномерное распределение рабочей силы в границах туристского региона: миграция в период высокого сезона в регионах/городах с наибольшей концентрацией туристских ресурсов, развитой туристской инфраструктурой, более высоким уровнем заработной платы; форс-мажорные обстоятельства и др.

Отмеченные характерные черты непосредственным образом сказываются на ситуации на рынке труда региона, являющегося источником рабочей силы, и соответственно, объясняющим необходимость учета его состояния, прежде всего, в процессе поиска и подбора (рекрутинга) персонала гостиничными предприятиями. Принимая во внимание данную особенность управления персоналом, предприятиям следует отслеживать ситуацию на рынке труда конкретного региона и адаптироваться к нему. Решая данную задачу, предприятия могут пользоваться информацией, предлагаемой официальными источниками государственных учреждений (органы статистики, профильные министерства и ведомства и др.), кадровых агентств и крупных рекрутинговых компаний, представляющих информацию в сети Интернет. 
Среди последних особое место занимают сервисы компании «HeadHunter». Например, чтобы получить представление о современной ситуации (2019-2020 гг.) на рынке труда Крыма в индустрии гостеприимства, следует изучить показатели, представленные на [Статистика HeadHunter по Республике Крым, 2021], основным из которых является hh.индекс (рис. 2).

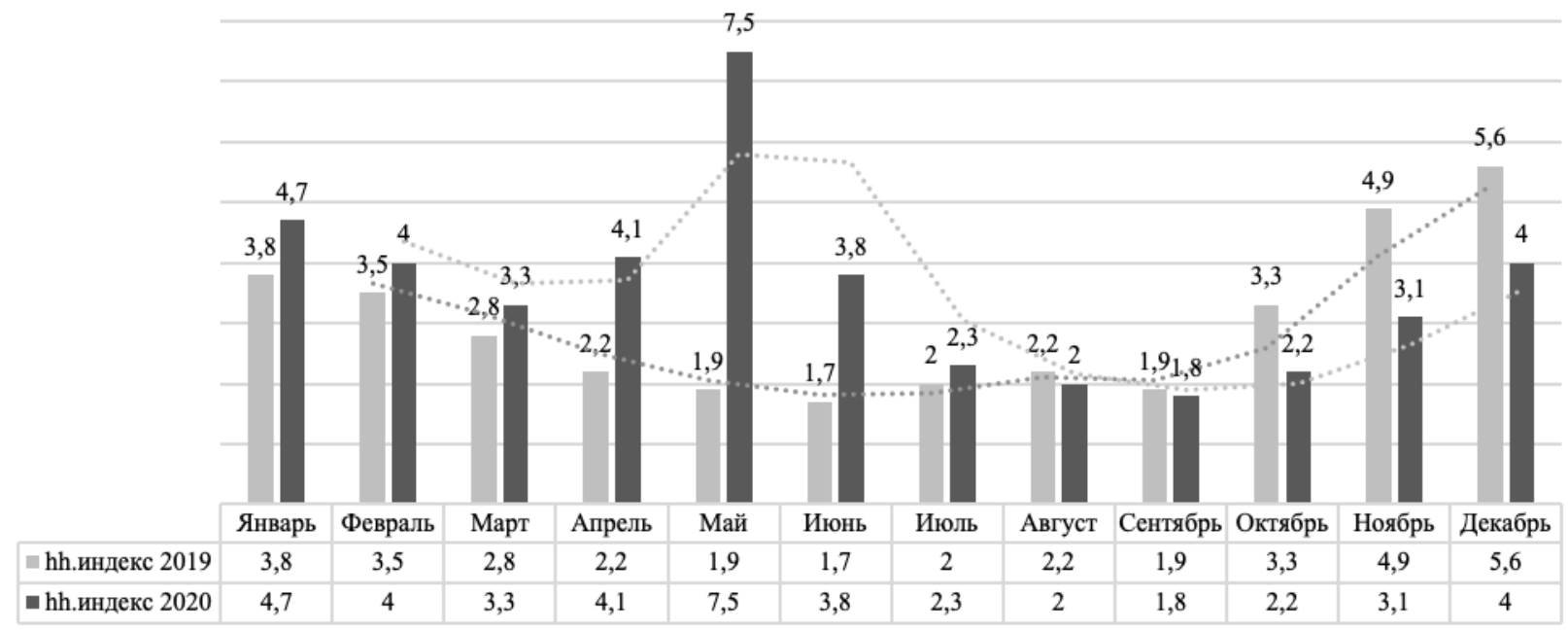

Рис. 2. Динамика hh.индекса индустрии гостеприимства

(профессиональной сферы «туризм, гостиницы, рестораны») в Республике Крым (2019-2020 гг.) Fig. 2. Dynamics of the hh.index of the hospitality industry (the professional sphere including tourism, hotels and restaurants) and the seasonal coefficient in the Republic of Crimea (2019-2020)

С целью определения и представления тенденций анализируемого показателя за исследуемый период используем метод скользящей средней, позволяющей сглаживать краткосрочные колебания и выделять основные циклы. Как отмечалось ранее, динамика показателя до 2019 г. имела четко выраженную сезонную тенденцию, сохранявшуюся на протяжении ряда предшествующих лет. В то же время неустойчивый характер спроса на услуги гостиничных предприятий региона и сезонность открытия вакансий не позволяют делать однозначный вывод в отношении типа исследуемого рынка (рынок работодателя или рынок соискателя): в зависимости от рассматриваемого сезона (высокий/низкий), и как следствие, поочередной и закономерного превышения предложения (количества вакансий) над спросом (количеством резюме), и наоборот, рынок труда обозначенного туристского региона приобретает соответствующие черты того или иного типа рынка.

Таким образом, гостиничные предприятия того или иного региона могут отслеживать и анализировать информацию о состоянии рынка труда с целью регулирования процесса поиска и подбора персонала.

Категория и специализация. Категория и специализация гостиничного предприятия оказывает заметное влияние на управление персоналом всех уровней и квалификаций. Категория гостиничного предприятия характеризуется количеством звезд, и чем выше уровень звездности/класса, тем разнообразнее (шире) ассортимент услуг, что в свою очередь, влияет на состав и количество подразделений отеля. Специализация предполагает ориентацию средства размещения на определенные виды туризма: деловой туризм, экскурсионный, лечебный и др. Соответственно, специализация характеризует тип гостиничного предприятия: санаторий, конгресс-отель, SPA-отель и т. д. Особенность управления персоналом, обусловленная зависимостью от категории и специализации средства размещения, выражается в том, что к персоналу предъявляются особые требования к: квалификации, опыту работы, профессиональным компетенциям, знанию языков и т. д.

Также наличие определенных требований и установленных гостиничным предприятием стандартов к сотрудникам узкого профиля с определёнными требованиями к квалификации для 
продвижения и реализации дополнительных гостиничных услуг, ориентированных на выделенный сегмент рынка туризма (для санатория в приоритете будут квалифицированные медицинские работники, а в бизнес-отеле может вообще отсутствовать медицинский профиль и услуги рекреации). Фактор «категория» предполагает наличие определённых стандартов в гостиничной индустрии, в том числе и стандартов, установленных к персоналу. Положение о классификации гостиниц в РФ [Постановление Правительства РФ, 2020] содержит в себе общие бальные требования к персоналу, предъявляемые к различным категориям гостиниц.

Требования к персоналу будут изменяться и в зависимости от специализации средства размещения (профессиональные компетенции, квалификация, опыт работы). Например, средство размещения, ориентированное на рекреационный туризм, может классифицироваться как санаторно-курортное учреждение. В таком случае, специализация предприятия будет выражаться в наличии медицинского профиля, оздоровительных программ, что, в свою очередь, потребует наличия у сотрудников, предоставляющих медицинские услуги, медицинского образования. Такой тип гостиничного предприятия как конгресс-отель будет ориентирован на деловой туризм и на определенные конференц-группы, что потребует дополнительных требований в области знания иностранных языков.

Форма собственности и организации управления предприятием, относясь к числу факторов, связанных с организацией и ведением гостиничного бизнеса, непосредственным образом сказывается и на организационных аспектах управления персоналом. В частности, на организацию системы управления персоналом гостиничных предприятий оказывает влияние:

- сотрудничество с сетевыми гостиничными отелями (является ли гостиница независимым отелем или входит в гостиничную сеть, осуществляя свою деятельность на условиях франчайзинга);

- форма собственности субъекта ведения хозяйственной деятельности (гостиничного предприятия): частная, муниципальная, федеральная, собственность субъектов РФ; предприятия, находящиеся в частной собственности, имеют возможность более гибко подходить к использованию HR-технологий и инструментов, оперативно реагируя на изменения, происходящие во внешней среде.

Ключевым фактором, предопределяющим различия в подходе к управлению персоналом гостиничных предприятий различной формы организации управления, является система мониторинга гостиничной деятельности предприятия: в сетевых отелях все процессы контролирует и осуществляет головной офис (управляющая компания).

Размер гостиничного предприятия также является одним из факторов, влияющим на управление персоналом. Данный фактор проявляется, прежде всего, во вместимости гостиничного предприятия (номерной фонд) и также определяет:

- сложность организационной структуры управления (на малых предприятиях она более простая),

- численность и обязанности персонала (в зависимости от вместимости гостиничного предприятия, количества отделов и функций, формируется необходимый штат сотрудников),

- регламент обслуживания (определяются стандарты),

- объем используемых цифровых технологий (степень цифровизации),

- систему построения служб маркетинга (в средних и крупных предприятиях создаются специальные службы маркетинга, проводятся маркетинговые исследования, а в малых предприятиях отсутствуют специализированные службы маркетинга, а функции маркетинга выполняет специалист по сбыту) и др.

Исходя из этого можно сформулировать такую особенность управления персоналом, как зависимость структурных характеристик гостиничных предприятий, функционала HRслужб и степени цифровизации от размера предприятия. 
Отметим также, что существуют различия в направлениях работы HR-подразделений в зависимости от размера предприятия. На средних и крупных предприятиях уделяется большое внимание созданию и продвижению бренда работодателя, поиску и подбору узкопрофильного персонала, а также адаптации и обучении персонала. В малых отелях часто наблюдается минимальная роль инвестиций в развитие и обучение персонала.

Группировка факторов влияния. Таким образом, проведенное исследование и определение причинно-следственных связей между отраслевыми факторами, влияющими на управление персоналом гостиничных предприятий, и выделенными особенностями управления персоналом, позволяют дифференцировать последние, сгруппировав их следующим образом: факторы, характеризующие особенности и состояние индустрии гостеприимства; факторы, связанные с организацией и ведением бизнеса с индустрии гостеприимства.

Однако представленные группы отраслевых факторов не исчерпывающим образом характеризуют влияние на деятельность гостиничных предприятий и HR бизнес-процессы в частности. В этой связи возникает необходимость выделения дополнительных факторов, носящих глобальный характер, но оказывающих значимое влияние на обозначенные процессы в современных условиях. К числу глобальных факторов можно отнести неблагоприятную эпидемиологическую ситуацию (пандемия Covid-19, коронакризис) и продолжающуюся цифровую трансформацию бизнеса (переход к цифровой экономике). Из приведенных ранее результатов исследования можно заключить, что обозначенные факторы могут оказывать влияние на процессы управления персоналом прямым и опосредованным образом (рис. 3).

Представленная концептуальная модель характеризуется причинно-следственными связями, выявленными в процессе анализа отраслевых факторов, оказывающих влияние на особенности управления персоналом гостиничных предприятий; главными взаимосвязями являются связи между группами факторов и особенностями, так как именно они определяют характер взаимодействия; изменение таких факторов как эпидемиологическая ситуация и цифровая трансформация бизнеса влияет на обе группы факторов, связанных с организацией и ведением гостиничного бизнеса и факторами, характеризующими особенности и состояние индустрии гостеприимства.

\section{Заключение}

В заключении следует сделать вывод, что успех управления персоналом гостиничного предприятия в условиях влияния глобальных факторов (цифровизация экономики и коронакризис) во многом зависит от комплексного подхода к рассмотрению и определению ключевых отраслевых факторов, оказывающих непосредственное влияние на управление персоналом гостиничного предприятия. Целостно выстроенная модель понимания структурно-логических и причинно-следственных связей влияния факторов на особенности управления персоналом сможет стать для HR-специалиста гибким инструментом эффективного управления, способствуя оперативному принятию решений, инициированию и быстрой адаптации к сложившимся условиям отрасли, прогнозированию возможностей и угроз, а также разработке долгосрочной стратегии управления предприятием в целом с опорой на выявленные факторы и особенности управления персоналом.

Умение четко видеть и оценивать причины (факторы) позволяет спрогнозировать экономически плодотворные и выгодные решения с учетом ключевых характеристик (особенностей) управления персоналом, что и является определяющим при разработке стратегии управления персоналом гостиничного предприятия. 


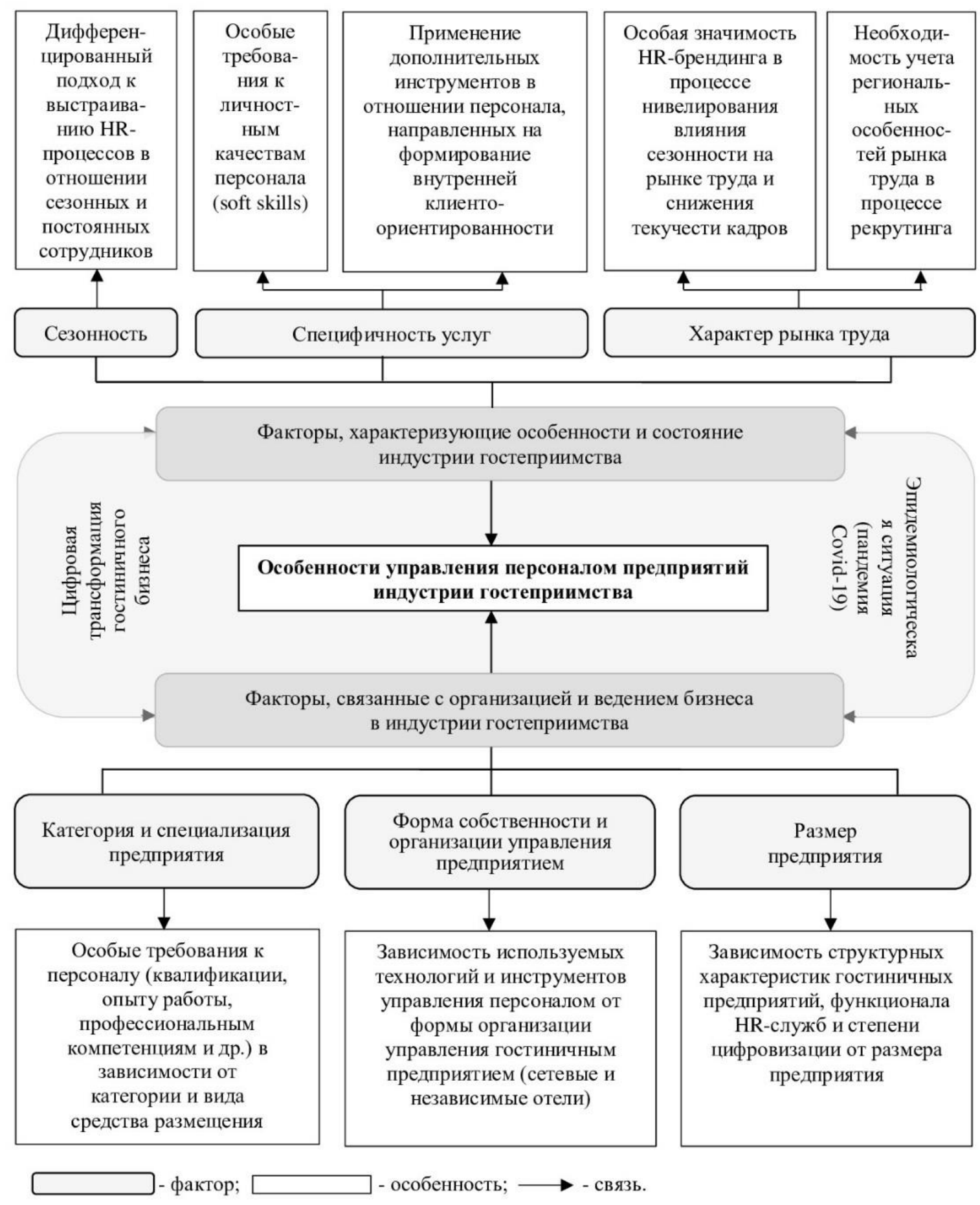

Рис. 3. Концептуальная модель влияния отраслевых факторов индустрии гостеприимства на особенности управления персоналом гостиничных предприятий в современных условиях

Fig. 3. The conceptual influence pattern of sector-specific factors of the hospitality industry on the features of personnel management at hotel establishments under the present-day conditions

\section{Список литературы}

1. Архипова Н.И., Данилова Д.В. 2019. Особенности подбора и отбора персонала в гостиничном бизнесе. В кн.: Фундаментальные и прикладные научные исследования: актуальные вопросы, достижения и инновации. Сборник трудов конференции (Пенза, 13 июля 2019 года). Пенза, 
Изд-во Наука и просвещение: 111-116. URL: https://www.elibrary.ru/item.asp?id=39148656 (дата обращения: 24.12.2020).

2. Вертинова А.А., Бородина Д.М., Воронова К.Н. 2019. Диджитализация сферы управления персоналом. Карельский научный журнал. 3 (28): 81-83 URL: https://cyberleninka.ru/article/ n/didzhitalizatsiya-sfery-upravleniya-personalom (дата обращения: 23.12.2020).

3. Гордеева Е.В., Бурова В.В. 2020. Актуальные проблемы в сфере управления персоналом в период распространения COVID-19 в России и за рубежом. Экономика и бизнес: теория и практика. 10-1: 76-79. URL: https://www.elibrary.ru/item.asp?id=44210378 (дата обращения: 23.12.2020).

4. Кузнецова T.A. 2019. Внедрение digital-технологий в сферу управления человеческими peсурсами. Экономика и бизнес: теория и практика. 9: 111-115. URL: https://cyberleninka.ru/article/n/vnedrenie-digital-tehnologiy-v-sferu-upravleniya-chelovecheskimi-resur sami (дата обращения: 04.01.2021).

5. Сайфуллина Л.Д., Комнатная А.В. 2020. Влияние пандемии на автоматизацию основных задач HR-специалиста. Экономика и бизнес: теория и практика. 9-2: 52-56. URL: https://cyberleninka.ru/article/n/vliyanie-pandemii-na-avtomatizatsiyu-osnovnyh-zadach-hr-spetsialista (дата обращения: 24.12.2020).

6. Лустина Т.Н., Арутюнян А.А. 2018. Особенности управления персоналом в гостиничном бизнесе. В кн: Традиционная и инновационная наука: история, современное состояние, перспективы. Сборник трудов конференции (Пермь, 10 января 2018 года). Пермь, Изд-во НИЦ Аэтерна: 162-165. URL: https://aeterna-ufa.ru/sbornik/NK-204-1.pdf\#page=162 (дата обращения: 24.12.2020).

7. Мартынова М.Э., Камшилов С.Г. 2019. Цифровые технологии в управлении персоналом компании. Общество, экономика, управление. 4: 69-74. URL: https://cyberleninka.ru/article/ n/tsifrovyetehnologii-v-upravlenii-personalom-kompanii (дата обращения: 21.12.2020).

8. Михайлов А.А., Федулов В.И. 2020. Подходы к управлению персоналом в условиях удаленной занятости. ЕГИ. 3 (29): 222-226. URL: https://cyberleninka.ru/article/n/podhody-k-upravleniyupersonalom-v-usloviyah-udalennoy-zanyatosti (дата обращения: 21.12.2020).

9. Мысова О.С. 2015. Специфика управления персоналом как подсистемы гостиничного менеджмента. Вестник КемГУ. 1-4 (61): 230-234. URL: https://cyberleninka.ru/article/n/spetsifikaupravleniya-personalom-kak-podsistemy-gostinichnogo-menedzhmenta (дата обращения: 21.12.2020).

10.Нагибина Н.И., Щукина A.A. 2017. HR-Digital: цифровые технологии в управлении человеческими ресурсами. Вестник евразийской науки. 1 (38): 1-17. URL: https://naukovedenie.ru/PDF/24EVN117.pdf (дата обращения: 24.12.2020).

11.Павлова М., Никольская Е.Ю. 2016. Особенности системы управления персоналом в индустрии гостеприимства. Инновационная наука. 3-1 (15): 175-182. URL: https://cyberleninka.ru/article/n/osobennosti-sistemy-upravleniya-personalom-v-industrii-gostepriimstva (дата обращения: 23.12.2020).

12.Постановление Правительства РФ от 18 ноября 2020 года №1860 «Положение о классификации гостиниц».

13.Савчишкина Е.П. 2009. Система управления персоналом залог эффективной деятельности организаций сферы гостеприимства. Terra Economicus. 3-3: 82-85. URL: https://cyberleninka.ru/ article/n/sistema-upravleniya-personalom-zalog-effektivnoy-deyatelnosti-organizatsiy- sfery-gostepriimstva (дата обращения: 23.12.2020).

14.Семина А.П. 2020. Цифровизация процессов управления персоналом: SMM в HR. Дискуссия. 1 (98): 62-68. URL: https://cyberleninka.ru/article/n/tsifrovizatsiya-protsessov-upravleniyapersonalom-smm-v-hr (дата обращения: 24.12.2020).

15.Статистика по России. Южный федеральный округ. Республика Крым. Head Hunter. URL: https://stats.hh.ru/republic_of_crimea (дата обращения: 24.01.2021).

16.Тимиргалеева Р.Р., Гришин И.Ю., Шостак М.А. 2015. Управление развитием предприятий туристско-рекреационной сферы на основе внутреннего маркетинга. Симферополь, Ариал, 307. URL: https://www.elibrary.ru/download/elibrary_24006828_82942025.pdf (дата обращения: 24.12.2020).

17.Чуваткин П.П., Горбатов С.А. 2020. Управление персоналом гостиничных предприятий. М., Юрайт, 280. URL: https://urait.ru/bcode/447423 (дата обращения: 21.12.2020).

18.Шавровская М.Н. 2011. Клиентоориентированность персонала: формирование и оценка. Автореф. дис. ... канд. экон. наук, Омск. URL: http://www.dslib.net/economikaxoziajstva/klientoorientirovannost-personala-formirovanie-i-ocenka.html (дата обращения: 24.12.2020). 
19.Шостак M.A. 2020. HR-digital: основные направления использования цифровых технологий в управлении человеческими ресурсами гостиничных предприятий. $\mathrm{B}$ кн.: Повышение конкурентоспособности социально-экономических систем в условиях трансграничного сотрудничества регионов. Сборник трудов конференции (Ялта, 2-4 апреля 2020 года). Симферополь, Изд-во Ариал URL: https://www.elibrary.ru/item.asp?id=44168675 (дата обращения: 21.12.2020).

20.Яковлева М.А. 2020. Влияние цифровой экономики на рынок труда. В кн.: Управленческий и сервисный потенциал цифровой экономики: проблемы и перспективы. Сборник трудов конференции (Омск, 14-15 мая 2020 года). Омск, Изд-во ОмГТУ. URL: https://www.elibrary.ru/item.asp?id=43114502 (дата обращения: 21.12.20201).

21.Яковлева М.А., Шостак М.A. 2020. Применение концепции Well-being предприятиями индустрии гостеприимства. Human Progress. 2: 1-7. URL: http://progresshuman.com/images/2020/Tom6_2/Yakovleva.pdf (дата обращения: 24.12.2020).

\section{References}

1. Arhipova N.I., Danilova D.V. 2019. Features of the selection and selection of personnel in the hotel business. In: Fundamental'nye i prikladnye nauchnye issledovanija: aktual'nye voprosy, dostizhenija i innovacii. Materialy mezhdunarodnoy nauchnoy konferentsii [Fundamental and Applied Research: Current Issues, Achievements and Innovation. Proceedings of the conference] (Penza, 13 July 2019) Penza, Publishing house Science and education: 111-116. URL: https://www.elibrary.ru/ item.asp?id=39148656 (accessed: 24.12.2020).

2. Vertinova A.A., Borodina D.M., Voronova K.N. 2019. Digitalization of the sphere of personnel management. Karelian scientific journal. 3 (28): 81-83. URL: https://cyberleninka.ru/ article/n/didzhitalizatsiya-sfery-upravleniya-personalom (accessed: 23.12.2020).

3. Gordeeva E.V., Burova V.V. 2020. Actual problems in the field of personnel management during the spread of COVID-19 in Russia and abroad. Economics and business: theory and practice. 10-1: 76-79. URL: https://www.elibrary.ru/item.asp?id=44210378 (accessed: 23.12 .2020 ).

4. Kuznecova T.A. 2019. Implementation of digital technologies in the field of human resource management. Economics and business: theory and practice. 9: 111-115. URL: https://cyberleninka.ru/ article/n/vnedrenie-digital-tehnologiy-v-sferu-upravleniya-chelovecheskimi-resursami (accessed: 04.01.2021).

5. Sajfullina L.D., Komnatnaja A.V. 2020. The impact of the pandemic on the automation of the main tasks of an HR specialist. Economics and business: theory and practice. 9-2: 52-56. URL: https://cyberleninka.ru/article/n/vliyanie-pandemii-na-avtomatizatsiyu-osnovnyh-zadach-hr-spetsialista (accessed: 24.12.2020).

6. Lustina T.N., Arutjunjan A.A. 2018. Features of personnel management in the hotel business. In: Tradicionnaja i innovacionnaja nauka: istorija, sovremennoe sostojanie, perspektivy. Materialy mezhdunarodnoy nauchnoy konferentsii [Traditional and innovative science: history, current state, prospects. Materials of international scientific conference] (Perm, January 10, 2018). Perm, SIC Aeterna publishing house: 162-165. URL: https://aeterna-ufa.ru/sbornik/NK-204-1.pdf\#page=162 (accessed: 24.12.2020).

7. Martynova M.Je., Kamshilov S.G. 2019. Digital technologies in personnel management of the company. Society, economics, management. 4: 69-74. URL: https://cyberleninka.ru/article/n/tsifrovyetehnologii-v-upravlenii-personalom-kompanii (accessed: 21.12.2020).

8. Mihajlov A.A., Fedulov V.I. 2020. Approaches to personnel management in remote employment. EGI. 3 (29): 222-226. URL: https://cyberleninka.ru/article/n/podhody-k-upravleniyu-personalom-vusloviyah-udalennoy-zanyatosti (accessed: 21.12.2020).

9. Mysova O.S. 2015. The specifics of personnel management as a subsystem of hotel management. Vestnik KemGU. 1-4 (61): 230-234. URL: https://cyberleninka.ru/article/n/spetsifika-upravleniyapersonalom-kak-podsistemy-gostinichnogo-menedzhmenta (accessed: 21.12.2020).

10.Nagibina N.I., Shhukina A.A. 2017. HR-Digital: digital technologies in human resource management. Bulletin of Eurasian Science. 1 (38): 1-17. URL: https://naukovedenie.ru/ PDF/24EVN117.pdf (accessed: 24.12.2020).

11.Pavlova M., Nikol'skaja E.Ju. 2016. Features of the personnel management system in the hospitality industry. Innovative Science. 3-1 (15): 175-182. URL: https://cyberleninka.ru/ article/n/osobennosti-sistemyupravleniya-personalom-v-industrii-gostepriimstva (accessed: 23.12.2020).

12.Decree of the Government of the Russian Federation of November 18, 2020 No. 1860 «Regulations on the classification of hotels». 
13. Savchishkina E.P. 2009. The personnel management system is the key to the effective operation of hospitality organizations. Terra Economicus. 3-3: 82-85. URL: https://cyberleninka.ru/article/n/sistemaupravleniya-personalom-zalog-effektivnoy-deyatelnosti-organizatsiy-sfery-gostepriimstva (accessed: 23.12.2020).

14.Semina A.P. 2020. Digitalization of HR processes: SMM in HR. Discussion. 1 (98): 62-68. URL: https://cyberleninka.ru/article/n/tsifrovizatsiya-protsessov-upravleniya-personalom-smm-v-hr (accessed: 24.12.2020).

15.Statistics for Russia. Southern Federal District. Republic of Crimea. Head Hunter. URL: https://stats.hh.ru/republic_of_crimea (accessed: 24.01.2021).

16.Timirgaleeva R.R., Grishin I.Yu., Shostak M.A. 2015. Management of the development of enterprises in the tourism and recreation sector based on internal marketing. Simferopol, Arial, 307. URL: https://www.elibrary.ru/download/elibrary_24006828_82942025.pdf (accessed: 24.12.2020).

17.Chuvatkin P.P., Gorbatov S.A. 2020. Personnel management of hotel enterprises. M., Yurayt, 280. URL: https://urait.ru/bcode/447423 (accessed: 21.12.2020).

18.Shavrovskaja M.N. 2011. Klientoorientirovannost' personala: formirovanie i ocenka [Customer focus of staff: formation and assessment]. Abstract. dis. ... cand. econom. sciences. Omsk. URL: http://www.dslib.net/economika-xoziajstva/klientoorientirovannost-personala-formirovanie-i-ocenka.html (accessed: 24.12.2020).

19.Shostak M.A. 2020. HR-digital: the main directions of using digital technologies in human resource management of hotel enterprises. In: Povyshenie konkurentosposobnosti social'no-jekonomicheskih sistem v uslovijah transgranichnogo sotrudnichestva regionov [Increasing the competitiveness of socio-economic systems in the context of cross-border cooperation of regions. Materials of international scientific conference] (Yalta, 02-04 April 2020), Simferopol, Arial Publishing House. URL: https://www.elibrary.ru/item.asp?id=44168675 (accessed: 21.12 .2020 ).

20. Yakovleva M.A. 2020. The impact of the digital economy on the labor market. In: Upravlencheskij i servisnyj potencial cifrovoj jekonomiki: problemy i perspektivy [Management and service potential of the digital economy: problems and prospects. Materials of international scientific conference] (Omsk, May 1415, 2020), Omsk, Publishing house of OmSTU. URL: https://www.elibrary.ru/item.asp?id=43114502 (accessed: 21.12.20201).

21. Yakovleva M.A., Shostak M.A. 2020. Applying Well-being to Hospitality Enterprises. Human Progress. 2: 1-7. URL: http://progress-human.com/images/2020/Tom6_2/Yakovleva.pdf (accessed: 24.12.2020).

\section{ИНФОРМАЦИЯ ОБ АВТОРАХ}

Шостак Марина Анатольевна, старший преподаватель кафедры менеджмента и туристского бизнеса Крымского федерального университет им. В.И. Вернадского

Яковлева Мария Андреевна, обучающаяся, направление подготовки 38.03.02 «Менеджмент», Крымский федеральный университет им. В.И. Вернадского

\section{INFORMATION ABOUT THE AUTHORS}

Marina A. Shostak, Senior Lecturer of the Department of Management and Tourism Business, V.I. Vernadsky Crimean Federal University

Maria A. Yakovleva, student, specialty 38.03.02 «Management», V.I. Vernadsky Crimean Federal University 